\title{
NEUROPHYSIOLOGICAL CHANGES IN CONTEXT TO DURATION OF EXPOSURE IN INSULIN DEPENDENT AND NON INSULIN DEPENDENT DIABETES MELLITUS
}

\author{
Maitrey Pandya *1, Miral Damani ${ }^{2}$. \\ *1 MPT, Neurophysiotherapist, Arogyam Hospital, Rajkot, Gujarat, India. \\ ${ }^{2}$ MPT, Lecturer, School Of physiotherapy RK University, Rajkot, Gujarat, India.
}

\section{ABSTRACT}

Background: Diabetes mellitus is characterized by inability of the body to metabolize glucose properly. The prevalence of diabetes is rapidly rising all over the globe at an alarming rate. IDDM and NIDDM shows effect on central nervous system, peripheral nervous system, autonomic nervous system, cardiovascular system and other physiological system. A common complication due to the IDDM and NIDDM includes peripheral neuropathy, retinopathy, nephropathy and vascular complication. Insulin and non-insulin dependent diabetes mellitus - both affect the peripheral nervous system depending on the duration of exposure and blood glucose level.

Materials and Methods: 120 healthy individuals with IDDM and NIDDM were included (screened with SF-36), with age limit between 25 to 60 years. Those individuals having a history of hospitalization in last 1 year, acute fever, present history of radiculopathy and open wound were excluded. Nerve conduction studies of common peroneal, tibial and sural nerves were examined in both groups. Distal Latency, NCV and CMAP/SNAP were taken as outcome measures.

Result and Discussion: Bio-statistical analysis has been done using Mann-Whitney test. Result suggest that long duration of exposure has significant $(p<0.05)$ effect on Neurophysiological changes compare to short duration of exposure in IDDM and NIDDM. With longer exposure of diabetes, there is increase in latency, decrease in amplitude and NCV.

Conclusion: Long duration of exposure shows significant Neurophysiological changes compare to short duration of exposure in IDDM and NIDDM.

KEY WORDS: Insulin dependent diabetes mellitus (IDDM), Non-insulin dependent diabetes mellitus (NIDDM), Nerve conduction velocity (NCV).

Address for correspondence: Dr. Maitrey Pandya, MPT, Neurophysiotherapist, Arogyam Hospital, Rajkot, Gujrat, India. E-Mail: maitrey.pandya07@rku.ac.in

\begin{tabular}{|c|c|c|}
\hline \multicolumn{3}{|c|}{ Access this Article online } \\
\hline \multirow{2}{*}{$\begin{array}{l}\text { Quick Response code } \\
\text { DOI: } 10.16965 \text { /ijpr.2016.178 }\end{array}$} & \multicolumn{2}{|c|}{$\begin{array}{l}\text { International Journal of Physiotherapy and Research } \\
\text { ISSN 2321- } 1822 \\
\text { www.ijmhr.org/ijpr.html }\end{array}$} \\
\hline & $\begin{array}{l}\text { Received: 12-09-2016 } \\
\text { Peer Review: 12-09-2016 } \\
\text { Revised: None }\end{array}$ & $\begin{array}{l}\text { Accepted: 10-10-2016 } \\
\text { Published (O): 11-04-2017 } \\
\text { Published (P): 11-04-2017 }\end{array}$ \\
\hline
\end{tabular}

\section{INTRODUCTION}

Diabetes mellitus is characterized by chronic hyperglycemia with disturbance of carbohydrate, fat, and protein metabolism resulting from defects in insulin secretion, insulin action or both. The two broad categories of diabetes are designated - Insulin dependent and non insulin dependent. IDDM is the result of complete or near-total insulin deficiency. NIDDM is a heterogeneous group of disorders characterized by varying degrees of insulin resistance, impaired insulin secretion, and increased glucose production [1]. According to the Diabetes Atlas 2006 published by the International Diabetes Federa- 
tion, the number of people with diabetes in India currently around 40.9 million is expected to rise to 69.9 million by 2025 unless urgent preventive steps are taken [2].

Insulin dependent and non insulin dependent diabetes shows their effect on various physiological system like Central nervous system, peripheral nervous system, musculoskeletal system, autonomic nervous system and cardiovascular system $[3,4]$. Common complication due to the IDDM and NIDDM includes peripheral neuropathy, retinopathy, nephropathy and vascular complication. Insulin dependent and non insulin dependent diabetes mellitus, both affect the peripheral nervous system significantly [5]. Diabetic peripheral neuropathy (DPN) is the most distressing of all the chronic complications of diabetes and is a cause of significant disability and poor quality of life. The presence of peripheral diabetic neuropathy is suggested by complaints of numbness, pain, or both, usually in a symmetrical distribution and noticed first in the toes [6].

Electrophysiological studies have revealed a number of abnormalities in diabetic neuropathy.[7-10] Patients with signs of neuropathy have slower nerve conduction velocities and smaller amplitudes than those without symptoms $[11,12]$, which shows a close correlation between clinical findings and the degree of conduction changes [13, 14].

The prevalence of diabetic neuropathy appears parallel with duration of exposure of diabetes in both type 1 and type 2 diabetes. People with diabetes can develop neurological problems at any time, but the risk of developing diabetic neuropathy increases with duration of diabetes. [15] Few studies suggest that duration of diabetes is also a factor for neuropathy. Therefore the aim of the study was to find Neurophysiological changes in context to duration of exposure in insulin dependent and non insulin dependent diabetes mellitus.

Review of literatures: Arindam [16] had observed that there is significant correlation between peripheral neuropathy and duration of diabetes, age of patients and postprandial blood glucose level.

Major Sharmeen Sultan [17] had observed that neuronal dysfunction of sensory nerves appears after prolonged exposure to hyperglycemia.

Method: This was an observational cross sectional study which included 120 subjects. (IDDM - 40 and NIDDM - 80) Subjects between 25 to 60 years of age and individuals with IDDM and NIDDM screened with SF-36 (general health good and above) were included in the study. Subjects having present history of lower limb radiculopathy, history of hospitalization in last 1 year, open wound and acute fever were excluded from the study. The room temperature was maintained between $21{ }^{\circ} \mathrm{c}$ to $23^{\circ} \mathrm{c}$. The skin resistance was reduced by cleaning with spirit. Supra maximal stimulation was given for the nerve conduction examination.

Flow Chart 1: Procedure and Data Collection.

120 diabetic individuals were selected based on inclusion criteria and informed consent was taken.

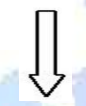

Screen with basic assessment form and NCV examination was performed on sural, tibial and peroneal nerves with RMS Aleron-2012 machine.

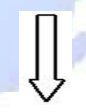

Distal latency, CMAP, SNAP and NCV were taken as outcome measures.

Bio-Statistical analysis was performed by using MannWhitney test in SPSS 21.

Surface recording for common peroneal nerve was obtained from extensor digitorum brevis and stimulation was given at the ankle and at the neck of the fibula. For Sural nerve examination, the surface electrode between lateral malleolus and tendoachilles, records nerve conduction of sural nerve. The nerve was stimulated antidromically $10-16 \mathrm{~cm}$ proximal to the recording electrode, distal to the lower border of gastrocnemius. The active surface recording electrode for tibial nerve was placed on abductor hallusis or abductor digiti quiniti, slightly below and anterior to navicular tuberosity. Surface stimulation was used behind and proximal to the medial malleolus and in the popliteal fossa.

Data Analysis: Bio-Statistical analysis was done using SPSS (version 21). Mann-Whitney test was used for data analysis. Level of significance was 0.05 . 


\section{RESULT}

Table 1 and 2 suggest that Duration has significant effect on neurophysiological changes in IDDM and NIDDM groups. Long duration of exposure shows major impact on neurophysiological changes in sural, tibial and peroneal nerve compared to short duration.

Graph 1 to 3 suggest that long duration of exposure has more increase in latency, more reduction in amplitude and more reduction in NCV compared to short duration of exposure.

Table 1: Neurophysiological changes in context to Duration of Exposure in Sural nerve.

\begin{tabular}{|c|c|c|c|c|}
\hline GROUP & \multirow{2}{*}{$\begin{array}{c}\text { DURATION } \\
\text { (years) }\end{array}$} & \multicolumn{3}{|c|}{ SURAL NERVE } \\
\hline \multirow[b]{2}{*}{$\begin{array}{l}\text { A-IDDM } \\
\text { B-NIDDM }\end{array}$} & & Latency & SNAP & NCV \\
\hline & $\begin{array}{l}1 \text { (>10 Years) } \\
2 \text { (<10Years) }\end{array}$ & $\mathrm{ms}$ & $\mu v$ & $\mathrm{~m} / \mathrm{s}$ \\
\hline A1 $(n-21)$ & $15.29 \pm 2.76$ & $3.89 \pm 0.59$ & $6.41 \pm 2.64$ & $36.76 \pm 2.91$ \\
\hline A2 (n-19) & $5.95 \pm 1.9$ & $3.08 \pm 0.67$ & $14.47 \pm 5.68$ & $39.74 \pm 2.51$ \\
\hline \multicolumn{2}{|c|}{ Mann Whitney test $(P<0.05)$} & $0.0002^{*}$ & $0.0001^{*}$ & $0.0004 *$ \\
\hline B1 (n-14) & $11.29 \pm 1.07$ & $3.79 \pm 0.74$ & $8.02 \pm 3.83$ & $37.35 \pm 2.28$ \\
\hline B2 $(n-66)$ & $5.5 \pm 2.01$ & $3.05 \pm 0.55$ & $15.48 \pm 5.48$ & $39.71 \pm 2.32$ \\
\hline \multicolumn{2}{|c|}{ Mann Whitney test $(P<0.05)$} & $0.0001 *$ & $0.0001 *$ & $0.0003^{*}$ \\
\hline
\end{tabular}

Table 2: Neurophysiological changes in context to Duration of Exposure in Tibial and Peroneal nerves.

\begin{tabular}{|c|c|c|c|c|c|c|}
\hline GROUP & \multicolumn{3}{|c|}{ TIBIAL NERVE } & \multicolumn{3}{c|}{ PERONEAL NERVE } \\
\hline \multirow{2}{*}{$\begin{array}{c}\text { A-IDDM } \\
\text { B-NIDDM }\end{array}$} & Latency & CMAP & NCV & Latency & CMAP & NCV \\
\cline { 2 - 7 } & $\mathrm{ms}$ & $\mathrm{mv}$ & $\mathrm{m} / \mathrm{s}$ & $\mathrm{ms}$ & $\mathrm{mv}$ & $\mathrm{m} / \mathrm{s}$ \\
\hline A1 (n-21) & $5.15 \pm 0.6$ & $4.36 \pm 1.44$ & $37 \pm 2.65$ & $5.4 \pm 0.61$ & $3.53 \pm 1.17$ & $36.48 \pm 3.16$ \\
\hline A2 (n-19) & $4.49 \pm 0.62$ & $6.15 \pm 1.29$ & $39.33 \pm 1.75$ & $4.64 \pm 0.62$ & $5.26 \pm 0.77$ & $38.83 \pm 2.04$ \\
\hline $\begin{array}{c}\text { Mann Whitney } \\
\text { test(P< } \mathbf{0 . 0 5})\end{array}$ & $0.0025^{*}$ & $0.0002^{*}$ & $0.0024^{*}$ & $0.0003^{*}$ & $0.0001^{*}$ & $0.0030^{*}$ \\
\hline B1 (n-14) & $5.17 \pm 0.66$ & $4.44 \pm 1.21$ & $37.26 \pm 2.5$ & $5.34 \pm 0.68$ & $3.69 \pm 1.2$ & $36.69 \pm 2.29$ \\
\hline B2 (n-66) & $4.5 \pm 0.62$ & $6.37 \pm 1.07$ & $39.29 \pm 1.7$ & $4.6 \pm 0.57$ & $5.19 \pm 0.58$ & $39.12 \pm 1.66$ \\
\hline $\begin{array}{c}\text { Mann Whitney } \\
\text { test(P< }<0.05)\end{array}$ & $0.002^{*}$ & $0.0002^{*}$ & $0.0028^{*}$ & $0.0003^{*}$ & $0.0001^{*}$ & $0.004^{*}$ \\
\hline
\end{tabular}

$*=$ suggests significant difference

Graph 1: Latency changes in context to Duration in Sural, Tibial and peroneal nerves.

\section{LATENCY}

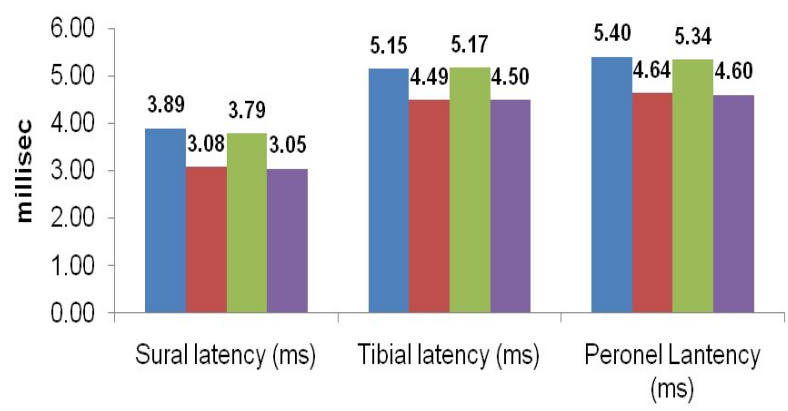

- A Long (>10y) $\square$ A Short (<10y) $\square \mathrm{B}$ Long (>10y) $-\mathrm{B}$ Short (<10y)
Graph 2: Amplitude changes in context to Duration in Sural, Tibial and peroneal nerves.

\section{AMPLITUDE}

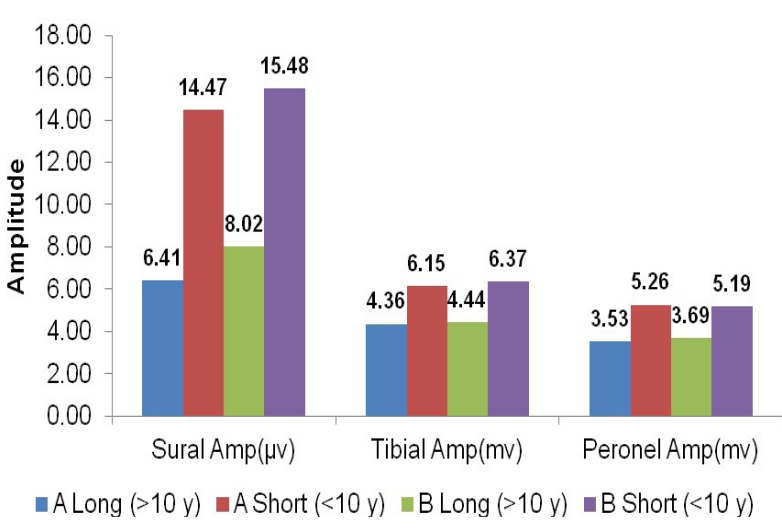

Graph 3: NCV changes in context to Duration in Sural, Tibial and peroneal nerves.

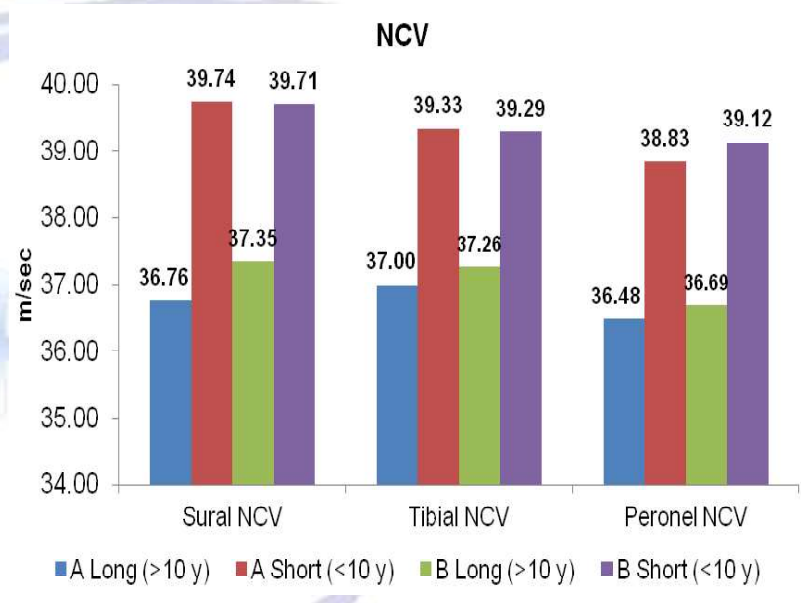

\section{DISCUSSION}

Duration of exposure has a significant effect on the peripheral nervous system. Our finding is consistent with the previous findings of Vinik, Gregersen, Valensi et al [18-20]. Knuiman et al [21] also reported that sensory neuropathy is more common in long standing diabetic subjects especially in those who develop the disease late in life. No significant sensory nerve dysfunction was found in the diabetic group with relatively short duration of diabetes. In hyperglycemias, glucose shunted through the Sorbitol pathway, causes the accumulation of sorbitol in Schwann cells, which undergoes osmotic damage leading to segmental demyelination. These changes indicate that duration of hyper glycemia plays a detrimental role on neurophysiological changes. Increase in latency and decreases in NCV are suggestive of demyelinating changes. While reduced amplitude is suggestive of axonal loss. [17] Here longer duration of exposure has more demyelinating and axonal changes compared to 
shorter duration of exposure in IDDM and NIDDM.

Future Study Scope: The study can be repeated to find the therapeutic effect of exercise on neurophysiological changes in context duration of exposure, The study can be repeated to find proximal nerve involvement in IDDM and NIDDM with different duration of exposure.

\section{CONCLUSION}

In context to this study and neurophysiological findings, individuals with long duration of exposure must be taken into consideration for promotion, prevention, and care as compared to short duration in IDDM and NIDDM for secondary complications.

\section{Conflicts of interest: None}

\section{REFERENCES}

[1]. AL Kakrani, Gokhale, Karan Vohra et al. Clinical and Nerve Conduction Study Correlation in Patients of Diabetic Neuropathy. Journal of the association of physicians of India. .2014;62:24-7.

[2]. Mohan, Sandeep, Deepa et al. Epidemiology of type 2 diabetes: Indian scenario. Indian Journal of medical research. 2007;125:217-30.

[3]. Lindsay, Bone, Callander. Neurology and neurosurgery illustrated. $3^{\text {rd }}$ edition. 1997:525.

[4]. Aspi and Sharukh Golwala.Medicine for students. $22^{\text {nd }}$ edition. 2009;437-44.

[5]. Mamta, Abigail, Catherine et al. Peripheral Neuropathy in Adolescents and Young Adults With Type1and Type2 Diabetes From the search for Diabetes in Youth Follow-up Cohort. American diabetes association. 2013;36:3903-9.

[6]. Callaghan, Little, Feldman et al. Enhanced glucose control for preventing and treating diabetic neuropathy (Review). The cohort collaboration.2012;6:155.

[7]. Jun Kimura M. D. Electro diagnosis in Diseases of Nerve and Muscle. Principles and Practice. $3^{\text {rd }}$ Ed.; 1987:653.

[8]. Claus, Mustafa, Vogel et al. Assessment of diabetic neuropathy. Definition of norm and discrimination of abnormal nerve function. Muscle nerve 1993;16:757-768.
[9]. Dyck, Karnes, Daube et al. Clinical and Neuro pathological criteria for the diagnosis and staging of diabetic polyneuropathy. Brain. 1985;108:861-880.

[10]. Mackel. Properties of cutaneous afferents in diabetic neuropathy. Brain. 1989;112:1359-1376

[11]. Niakan, Harati. Sympathetic skin response in diabetic peripheral neuropathy. Muscle nerve. 1988;11:261-264.

[12]. Le Quesne, Fowler, Parkhouse. Peripheral neuropathy profile in various groups of diabetics. Journal of neurology neurosurgery and psychiatry. 1990;53:558-563.

[13]. Halar, Graf, Halter et al. Diabetic neuropathy. A clinical, laboratory and electro diagnostic study. Archives of physical medicine and rehabilitation. 1982;63:298- 303.

[14]. Conrad, Aschoff, Fischler M.neurophysiological changes in patients with long duration diabetes.J Neurology. 1975;210:151-159.

[15]. Sultna, Begum, Hussain et al. Electrophysiological changes of motor nerves in patients with type 2 diabetes mellitus. Journal of armed forces medical college. 2009;5(2):14-17.

[16]. Arindam, Santa, Premchandra. Prevalence of peripheral neuropathy in newly diagnosed type 2 diabetics. International Journal of diabetes in developing country. 2005;25:30-3.

[17]. Major Sharmeen, Noorzahan, Ali et al. Electrophysiological changes of Sensory Nerves In Patients with Type-2 Diabetes Mellitus of Different Duration. BSMMU Journal. 2010;3(1):9-12

[18]. Vinik, Holland, Beua et al. Diabetic neuropathies. Diabetes care 1992;15(12):1926-1951.

[19]. Gregersen.Diabetic neuropathy, influence of age, sex, metabolic control and duration of diabetes on motor conduction velocity. Neurology 1967;17:972-980

[20]. Valensi, Giroux, Seeboth et al. Diabetic peripheral neuropathy: effects of age, duration of diabetes, glycemic control and vascular factors. Journal of Diabetes and its Complication. 1997;11:27-34

[21]. Kuniman, Wilborn, Mc Cann, et al. Prevalence of diabetic complications in relation to risk factors. Diabetes 1986;35:1332-1339.

\footnotetext{
How to cite this article:

Maitrey Pandya, Miral Damani. NEUROPHYSIOLOGICAL CHANGES IN CONTEXT TO DURATION OF EXPOSURE IN INSULIN DEPENDENT AND NON INSULIN DEPENDENT DIABETES MELLITUS. Int J Physiother Res 2017;5(2):1902-1905. DOI: 10.16965/ijpr.2016.178
} 